\title{
TERRITÓRIO E MODO DE VIDA QUILOMBOLA EM SÃO TOMÉ DE TAUÇÚ, NO RIO ACUTIPEREIRA, NO MUNICÍPIO DE PORTEL (PARÁ-BRASIL)
}

\author{
QUILOMBOLA TERRITORY AND WAY OF LIFE IN SÃO TOMÉ DE TAUÇÚ, IN RIO \\ ACUTIPEREIRA, IN THE MUNICIPALITY OF PORTEL (PARÁ-BRAZIL) \\ TERRITORIO QUILOMBOLA Y MODO DE VIDA EN SÃO TOMÉ DE TAUÇÚ, EN RÍO \\ ACUTIPEREIRA, EN EL MUNICIPIO DE PORTEL (PARÁ-BRASIL)
}

Christian Nunes da Silva ${ }^{1}$

http://lattes.cnpq.br/4284396736118279 http://orcid.org/0000-0001-7753-5394

Edinael Pinheiro da Silva ${ }^{2}$

http://lattes.cnpq.br/6626210009498720 https://orcid.org/0000-0002-5079-7121

\section{Ricardo Ângelo Pereira de Lima ${ }^{3}$ \\ http://lattes.cnpq.br/1993748824383678 https://orcid.org/0000-0002-3532-422X}

Hugo Pinon de Souza 4 http://lattes.cnpq.br/5603577519786368 https://orcid.org/0000-0002-6713-2556

\section{Geovani Gonçalves Farias 5 \\ http://lattes.cnpq.br/1514718571055552 \\ https://orcid.org/0000-0002-5842-7862}

Recebido em: 8 de junho de 2020

Aprovado em: 15 de julho de 2020

RESUMO: O artigo objetiva analisar o modo de vida dos quilombolas de São Tomé de Tauçú, no rio Acutipereira, no município de Portel (PA). Para isso, foram

\footnotetext{
${ }^{1}$ Doutor em Ecologia. Pós-Doutorando em Desenvolvimento Regional no PPGMDR/UNIFAP. Professor Adjunto II da Universidade Federal do Pará. Bolsista FAPEAP/CAPES. Pesquisador do GAPTA/CNPq. Docente do Programa de Pós-graduação em Geografia (PPGEO/UFPA). Sócio efetivo do Instituto Histórico e Geográfico do Pará. E-mail: cnsgeo@yahoo.com.br.

${ }^{2}$ Geógrafo e professor de Geografia, mestre em Geografia, pelo Programa de Pós-Graduação em Geografia (PPGEO) da Universidade Federal do Pará (UFPA) e membro do Grupo Acadêmico Produção do Território e Meio Ambiente na Amazônia (GAPTA-UFPA). E-mail: silvaepgeo@yahoo.com.br.

${ }^{3}$ Professor Associado II da Universidade Federal do Amapá (UNIFAP), pós-doutor em Geografia, pelo PPGEO/UFPA, bolsista FAPESPA/CAPES e pesquisador do GAPTA/CNPq. E-mail: ricardoangelo_pereira@yahoo.es.

${ }^{4}$ Geógrafo e professor de Geografia, mestre em Geografia, pelo Programa de Pós-Graduação em Geografia (PPGEO) da Universidade Federal do Pará (UFPA), bolsista CAPES e membro do Grupo Acadêmico Produção do Território e Meio Ambiente na Amazônia (GAPTA-UFPA).E-mail: hugosousa16@gmail.com.

${ }^{5}$ Geógrafo e professor de Geografia, mestre em Geografia, pelo Programa de Pós-Graduação em Geografia (PPGEO) da Universidade Federal do Pará (UFPA). E-mail: fariasgggeo@yahoo.com.br.
} 
realizadas as etapas de pesquisa bibliográfica, pesquisas em órgãos públicos e visitas em campo, que possibilitaram o entendimento e análise do modo de vida na comunidade estudada. A partir dos dados oriundos da observação e de entrevistas, observou-se que a inserção de novos agentes, políticas públicas e de culturas diversas está gerando modificações no modo de vida desses quilombolas, o que vem demandando adaptações que refletem diretamente na relação dos indivíduos com seu território.

Palavras-chave: Território. Modo de vida. Quilombolas. Amazônia.

ABSTRACT: The article aims to analyze the way of life of the quilombolas of São Tomé de Tauçú, on the Acutipereira River, in the municipality of Portel (PA). For this, the stages of bibliographic research, research in public agencies and field visits were carried out, which enabled the understanding and analysis of the way of life in the studied community. From the data from observation and interviews, it was observed that the insertion of new agents, public policies and different cultures is generating changes in the life style of these quilombolas, which has demanded adaptations that directly reflect on the relationship of individuals with their territory.

Keywords: Territory. Way of Life. Quilombolas. Amazon.

RESUMEN: El artículo tiene como objetivo analizar la forma de vida de las quilombolas de Santo Tomé de Tauçú, en el río Acutipereira, en el municipio de Portel (PA). Para ello, se llevaron a cabo las etapas de investigación bibliográfica, investigación en organismos públicos y visitas de campo, que permitieron la comprensión y el análisis de la forma de vida en la comunidad estudiada. A partir de los datos de observación y entrevistas, se observó que la inserción de nuevos agentes, políticas públicas y diferentes culturas está generando cambios en el estilo de vida de estas quilombolas, lo que ha exigido adaptaciones que reflejan directamente la relación de las personas con su territorio.

Palabras clave: Territorio. Modo de vida. Quilombolas. Amazonas.

\section{INTRODUÇÃO}

O presente trabalho tem como objetivo analisar o modo de vida dos habitantes do quilombo de São Tomé de Tuaçú, no município de Portel (PA), a partir de seu cotidiano e de suas formas de uso do território. Essa temática é um assunto de extrema importância, visto que o modo de vida quilombola se constituí na ligação afetiva entre o sujeito e o território vivido, ou seja, pelo vínculo de pertencimento que há entre este indivíduo e o meio ao qual suas práticas são desenvolvidas. Estas particularidades são responsáveis pela reorganização socioespacial e, certamente, demarcam e contribuem para o modo de vida de populações tradicionais.

Contudo, o modo de vida quilombola não se consolida no território apenas de modo material, mas, sobretudo, pela perspectiva simbólica e cultural destes quilombolas. Assim, neste território o quilombola sistematiza os mais distintos espaços que segundo Gusmão (1999) constitui um patrimônio comum e, por isso difere-se de terras de outros grupos. 
O território quilombola de São Tomé de Tauçú é composto por pessoas que possuem laços e traços únicos e particulares, aspectos simbólicos e culturais que retratam sua ascendência, são indivíduos que simbolizam gestos, estilos e generalidades inerentes de um sujeito quilombola.

De modo inicial, a partir da pesquisa, constatou-se que estes quilombolas foram conduzidos do Continente Africano no século XIX, mais ou menos no ano de 1863, sendo que no Pará se instalaram no rio Caruaca, município de curralinho no arquipélago do Marajó (PA). No ano de 1970 se transladaram para o rio Guajará ainda neste município e, posteriormente, no ano de 1972 migraram para o rio Acutipereira no município de Portel (PA), habitando o atual território que se denominou de Comunidade Remanescente de quilombo de São Tomé de Tauçú.

Frente aos fatos, para se execução deste trabalho, está tarefa seguiu os seguintes passos: pesquisa bibliográfica, em textos de livros e de revistas científicas, que forneceram os fundamentos teóricos para esta empreitada; levantamento de informações secundárias na prefeitura de Portel e em outros órgãos (INCRA, EMATER, ITERPA), que possibilitaram a obtenção de dados, a respeito do quilombo; pesquisa de campo realizada no período de 01/03 a 31/10/2019, efetivada com a aplicação de questionários, constituídos por questões semiestruturadas, e de entrevistas, com os sujeitos do quilombo, incrementada com registros fotográficos, com diálogos e com o acompanhamento do cotidiano de alguns dos entrevistados. Finalmente, realizaram-se as etapas de tratamento, de análise e de exposição dos dados coletados.

O texto também propõe um debate sobre a concepção de território e sobre o modo de vida dos habitantes desta comunidade, haja vista que, a partir destes conceitos, é possível perceber o dia a dia quilombola, suas práticas comunitárias e sua afinidade, para com o espaço ocupado. Nesse sentido, procura-se demonstrar o modo de vida local e, sobretudo, suas modificações, em função da chegada de agentes de origens culturais diversas, eminentemente baseados no sistema capitalista de produção, com outros ritmos, com outros tempos e com culturas urbanizadas. Desse modo, o texto se estrutura em uma discussão teórica sobre os conceitos principais da pesquisa e em uma posterior análise do estudo de caso.

\section{TERRITÓRIO E MODO DE VIDA, SOB UMA ÓTICA GEOGRÁFICA}

No debate geográfico, existem diversas concepções de território, tornando este vocábulo um conceito polissêmico. Partindo de tal premissa, a acepção clássica situa o território como espaço vital, proposto por Ratzel (MOREIRA, 1994). Este autor entendeu o território como um elemento indispensável, para o desenvolvimento e para a evolução de uma nação, devido aos recursos naturais/territoriais, que são limitados, o que influencia a busca e a incorporação de novos territórios, gerando conflitos entre indivíduos, grupos ou nações.

Nessa discussão, outro entendimento importante foi sugerido por Claude Raffestin (1993), para quem o território é a apropriação de uma fração do espaço, por um determinado grupo social ou por um ator sintagmático, no qual se percebem e se concebem relações de poder. Do ponto de vista de outros autores, como Gottmann (1973), Santos (1999) e Santos e Silveira (2001), o conceito de território decorre de seu tipo de uso, sendo considerado, ora como abrigo, ora como fonte de recursos. Para Gottmann (1973), o território tem um caráter concreto, material e político-ideológico, enquanto Santos (1999), apresenta o território como espaço usado e afirma que: 
(...) o território não é apenas o conjunto dos sistemas naturais e de sistemas de coisas superpostas. O território tem que ser entendido como o território usado, não o território em si. O território usado é o chão mais a identidade. A identidade é o sentimento de pertencer àquilo que nos pertence. O território é o fundamento do trabalho, o lugar da residência, das trocas materiais e espirituais e do exercício da vida (SANTOS, 1999, p. 08, grifo nosso).

Este mesmo autor sustenta que:

(...) nos atores hegemônicos o território usado é um recurso, garantia de realização de seus interesses particulares e para os "atores hegemonizados" corresponde a um abrigo, no qual buscam constantemente se adaptar ao meio geográfico local, ao mesmo tempo em que recriam estratégias que garantam sua sobrevivência nos lugares (SANTOS et al., 2000, p. 12-13).

Assim, o pensamento miltoniano denota que existe uma dependência mútua entre o território percebido com o conjunto de sistemas naturais e o território usado, visto que é a partir desta reciprocidade que se percebe quem são os atores hegemônicos e os hegemonizados.

Neste sentido, o território usado reúne "a interdependência e a inseparabilidade entre a materialidade, que inclui a natureza e o seu uso, o que inclui a ação humana, isto é, o trabalho e a política" (SANTOS; SILVEIRA, 2001, p. 247). E, partindo deste contexto que revela-se uma interrelação da natureza com a ação humana, em que pode-se aferir que estes agentes são inseparáveis, posto que o homem explora a natureza para a sua sobrevivência e a organiza de acordo com suas necessidades.

Frente à abordagem posta, existe por outro lado, visões, que privilegiam sua dimensão cultural e simbólica, como a de Haesbaert (2007) e a de Saquet (2009). Haesbaert (2007, p. 20) menciona que:

(...) desde sua origem, o território nasce com uma dupla conotação, material e simbólica, pois etimologicamente aparece tão próximo de terra-territorium quanto de terreo-territor (terror, terrorizar), ou seja, tem a ver com dominação (jurídico-política) da terra e com a inspiração do terror, do medo - especialmente para aqueles que, com esta dominação, ficam alijados da terra, ou no "territorium" são impedidos de entrar. Ao mesmo tempo, por outro lado, podemos dizer que, para aqueles que têm o privilégio de plenamente usufrú-lo, o território pode inspirar a identificação (positiva) e a efetiva "apropriação" (HAESBAERT, 2007, p. 20).

Na visão de Saquet (2009, p. 81): “(...) o território é produto de ações históricas que se concretizam em momentos distintos e sobrepostos, gerando diferentes paisagens, logo, é fruto da dinâmica sócio espacial". A visão deste autor revela que o território é uma construção histórica e, portanto, social, que se pauta nas relações de poder envolvendo sociedade e natureza, o que também se considera como espaço. Com isso, pode-se considerar que é no território que se percebe a constituição do modo de vida de uma dada coletividade.

A partir destas afirmações se percebe que é no território que se materializa o modo de vida, principalmente na relação do homem com a natureza, ou seja, por meio de práticas habituais manifestadas por uma determinada coletividade. Assim, as palavras de Silva (2006) nos mostram que o modo de vida e o território são produtos e reflexos da atuação dos indivíduos no 
espaço e no uso dos recursos naturais. Entretanto, para elucidar melhor esta afirmação, Silva (2006) constrói um esquema-síntese, que vislumbra os elementos formadores do modo de vida (Figura 1):

Figura 1 - Elementos formadores do modo de vida.

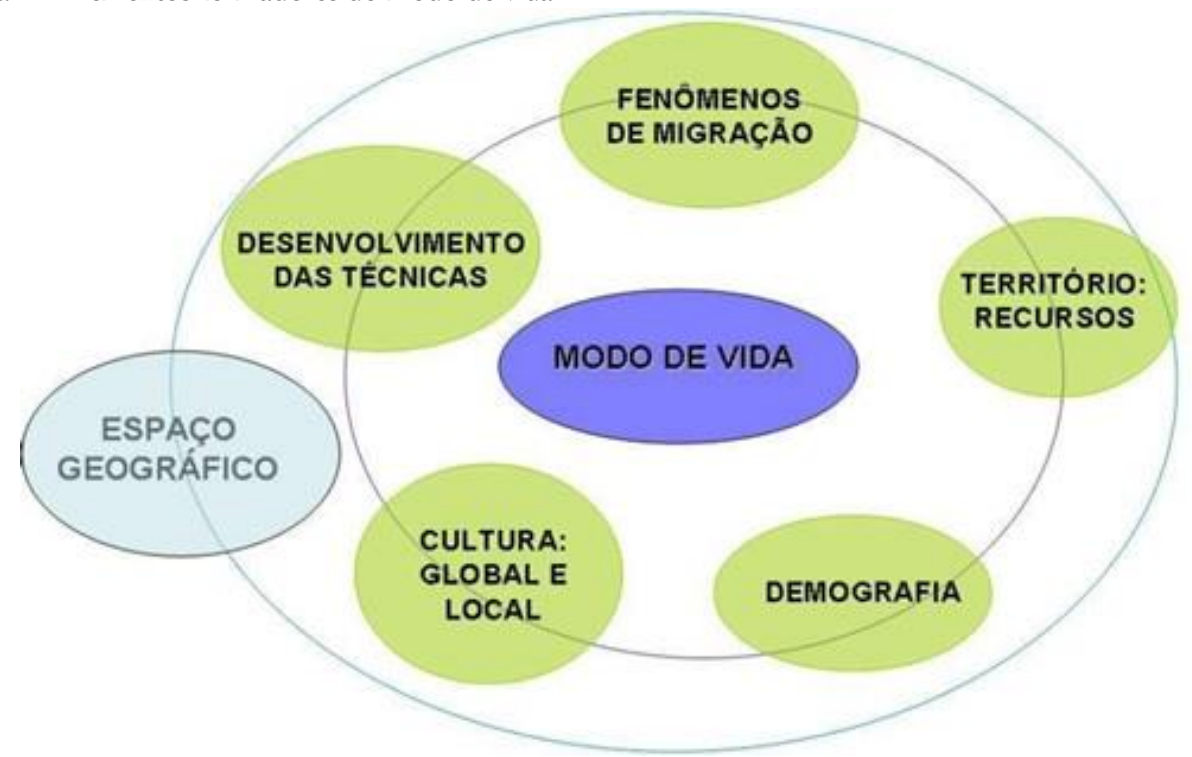

Fonte: Silva (2006).

Dado o exposto, nota-se que o modo de vida é uma constituição histórica, que é passada de geração em geração, consolidando-se no território. A este respeito, o modo de vida, ou o gênero de vida, nas palavras de Vidal de La Blache, se constitui como:

O homem criou para si modos de vida. Com o auxílio de materiais e de elementos tirados do meio ambiente conseguiu, não de uma só vez, mas por uma transmissão hereditária de processos e de invenções, constituir qualquer coisa de metódico que lhe assegura a existência e lhe organiza um território, meio para o seu uso. Caçador, pescador, agricultor - ele é tudo isso graças a uma combinação de instrumentos que são sua obra pessoal, sua conquista, aquilo que ajuntou por sua iniciativa à criação. (LA BLACHE, 1954, p. 162).

Nota-se o homem se adaptando ao ambiente, por meio da evolução da técnica, e, consequentemente, utilizando seus elementos, isto é, subtraindo os recursos territoriais essenciais à manutenção de sua vida, tais como: alimentos, vestimentas e moradia. Nesse sentido, este sujeito utiliza os elementos do território e, paralelo a isso, constitui um modo de vida próprio, no espaço em que subsiste.

Para Nahum (2011), o território é o chão, onde se cria a identidade da comunidade ${ }^{6}$. Uma identidade de "pertencer àquilo que nos pertence. Sendo também o lugar da residência, das trocas materiais e espirituais e do exercício da vida” (SANTOS; SILVEIRA, 2001, p. 19).

Estas afirmações remetem a um território onde o ser humano constitui, cria e estabelece seu próprio modo de vida, com seus laços e traços culturais, físicos, alimentares, crenças, apa-

${ }^{6}$ Entende-se por comunidade a aglomeração populacional e a existência de infraestruturas sociais, como: escola, posto de saúde, igrejas, abastecimento de água, serviços telefônicos, entre outros. Entende-se por território o espaço, onde existe uma organização social e onde os indivíduos se integram, solidificando relações humanas, sociais, políticas, econômicas e culturais (FERRAZ; CARDOSO, 2012). 
relhamento para o trabalho e, sobretudo, tendo o rio e a floresta como objetos simbólicos de seu mundo, visto que estes são para essas pessoas elementos de utilização material e imaterial.

Em outras palavras, Castro (1998, p. 7) verifica que:

O uso dos recursos da floresta e dos cursos d'água estão, portanto, presentes nos seus modos de vida, enquanto dimensões fundamentais que atravessam as gerações e fundam uma noção de território, seja como patrimônio comum e simbólico, seja como de uso familiar ou individualizado pelo sistema de posse ou pelo estatuto da propriedade privada.

Portanto, fortalecendo a abordagem exposta, nota-se que o modo de vida é compreendido como um elemento consolidado, a partir da apropriação do território, por meio de coletividades humanas e de comunidades, ao passo que seus costumes tradicionais se consolidam e laços e redes são constituídos, juntamente com o espaço, a partir do empoderamento sobre os elementos naturais do território.

\section{ASPECTOS DO MODO DE VIDA QUILOMBOLA DE SÃO TOMÉ DE TAUÇÚ}

O quilombo de São Tomé de Tauçú está localizado à margem esquerda do rio Acutipereira, no município de Portel, pertencendo à mesorregião do Marajó, na Amazônia Paraense (Figura 2), foi fundado no ano de 1972 e atualmente possui 40 famílias, totalizando 197 habitantes. Pode ser acessado, por via fluvial, em um deslocamento com duração de trinta minutos a duas horas, dependendo do tipo de embarcação utilizada e do sistema de marés, a partir da sede do município de Portel.

Figura 2 - Localização do Quilombo de São Tomé de Tauçú.

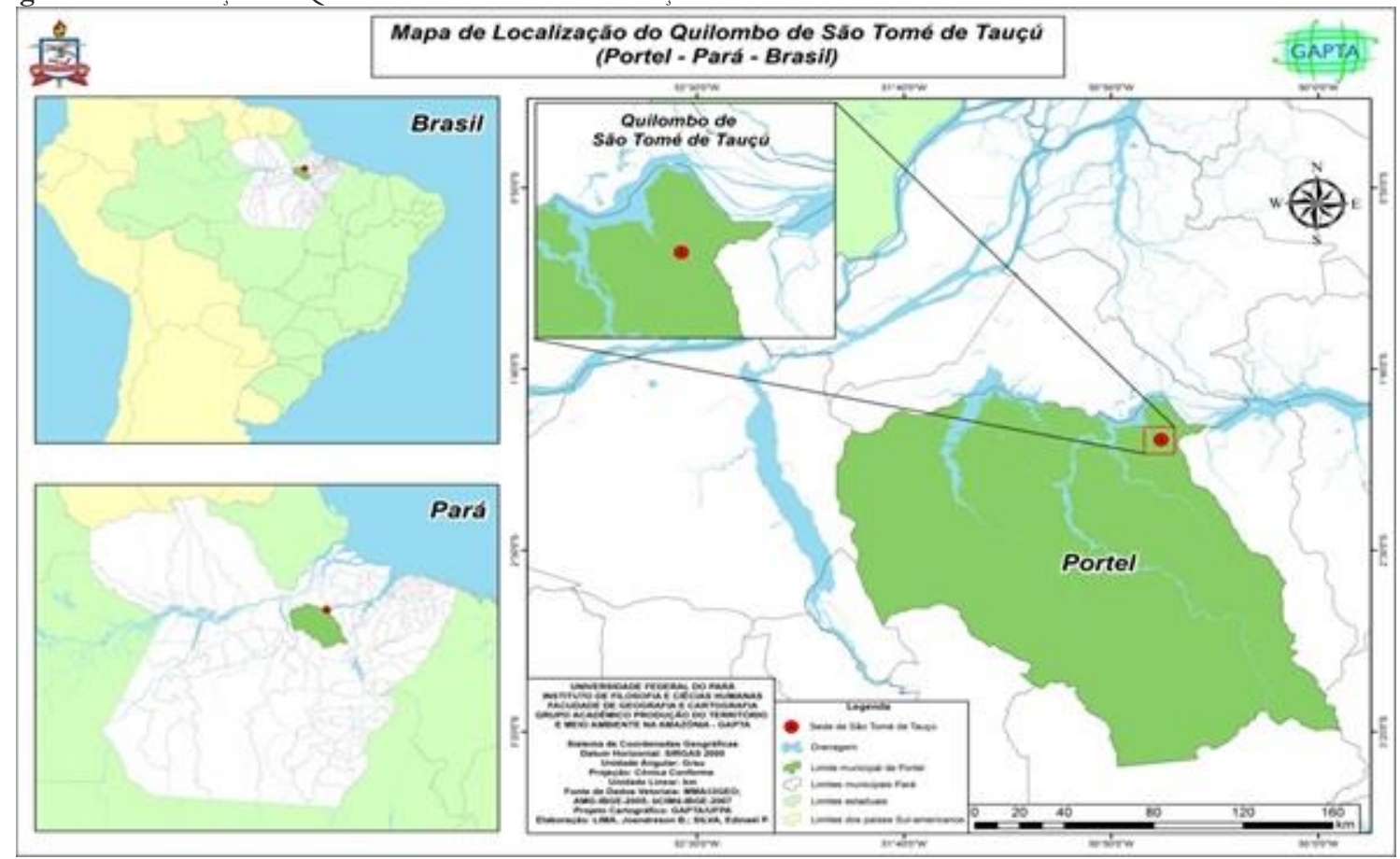

Fonte: Elaborado por Joandreson Lima e Edinael Silva (2019). 
Os quilombolas passaram a ser reconhecidos, pelo Estado brasileiro, a partir da promulgação da Constituição da República Federativa do Brasil de 1988 (BRASIL, 1988), por meio do Artigo 68 dos Atos das Disposições Constitucionais Transitórias (ADTC). Outra concepção proposta foi em 1994, no encontro da Associação Brasileira de Antropologia (ABA): “Toda comunidade negra rural que agrupe descendentes de escravos vivendo da cultura de subsistência e onde as manifestações culturais têm forte vínculo com o passado". O conceito mais atual é analisado por Almeida (2002) e Schmitt, Turatti e Carvalho (2002), que se baseando em estudos já efetivados, indica a partir de uma resposta do Conselho Ultramarino de 1740 a uma consulta do rei de Portugal que quilombo é "toda habitação de negros fugidos, que passem de cinco, em parte despovoada, ainda que não tenham ranchos levantados e nem se achem pilões nele".

Todavia, durante a pesquisa de campo, foi relatado, pelos entrevistados, que os quilombolas de São Tomé de Tauçú vêm perdendo o controle de seu território, por meio da proximidade com um assentamento ${ }^{7}$, instituído pelo Decreto $n^{0}$ 579, de 30 de outubro de 2012, que estabelece reserva específica de terras, para os usos das comunidades do rio Acutipereira, haja vista que este assentamento se encontra em processo de regularização, sob a tutela dos governos federal e estadual, por meio do Instituto Nacional de Colonização e Reforma Agraria/Assentamentos (INCRA) e do Instituto de Terras do Pará (ITERPA). Por conta destes fatos, notase a existência de uma relação de poder e de conflito, que se figura entre Estado e comunidade local, uma vez que o dia a dia deste povo está sujeito a um novo paradigma de gestão de território, divergente do modo de vida quilombola tradicional.

Todavia, é pertinente salientar que o povo, que integra este quilombo, já produzia neste território, antes, mesmo, de que fosse considerado uma reserva das comunidades ribeirinhas do rio Acutipereira. Estes quilombolas criaram vínculos de afetividade, haja vista que o modo pelo qual se apoderaram do território não está ligado, apenas, ao domínio físico, mas, sobretudo, a seus aspectos simbólicos, que evidenciam um sentimento de pertencimento a este espaço, por parte de tais indivíduos.

Diante dos fatos, percebe-se que o território dos quilombolas, que exibem saberes tradicionais ${ }^{8}$, vem sendo perpetuado, fundamentalmente, a partir de seu uso e de sua apropriação simbólica. Destarte, o objeto de estudo se fundamenta nas concepções de território, de Claude Raffestin (1993), considerando que este autor trata o território, a partir das relações de poder, nas quais se verifica a presença do Estado, de um lado (INCRA, em nível federal; ITERPA, em nível estadual), sobrepondo sua autoridade e, de outro, os moradores quilombolas de São Tomé de Tauçú, que vêm resistindo a esta proximidade. Os aportes teóricos de Santos (1999) e de Haesbaert (2007) auxiliam na compreensão deste fenômeno, quando tratam do uso e da apropriação simbólica e cultural do território, cujo processo é perceptível, no cotidiano destes aquilombados.

Os quilombolas de São Tomé de Tauçú exibem um modo de vida peculiar, que se assemelha

\footnotetext{
${ }^{7}$ Entende-se assentamento como um conjunto de unidades agrícolas, independentes entre si, instaladas pelo INCRA, aonde, originalmente, existia um imóvel rural, que pertencia a um único proprietário. Instituto Nacional de Colonização e Reforma Agrária/Assentamentos (INCRA). Disponível em: http://www.incra.gov.br. Acesso em: 12/07/2017.

8 Os saberes tradicionais são constituídos por conhecimentos de grupos humanos diferenciados, sob o ponto de vista cultural, que reproduzem historicamente seu modo de vida, de forma mais ou menos isolada, com base na cooperação social e em relações próprias com a natureza. Tal noção se refere, tanto aos povos indígenas quanto a segmentos da população nacional, que desenvolveram modos particulares de existência, adaptados a nichos ecológicos específicos (DIEGUES; ARRUDA, 2001, p. 21).
} 
ao dos ribeirinhos tradicionais, descendentes da cultura indígena da Amazônia, pois, como afirma Neves (2009), são policultores, agricultores e, complementarmente, pescadores, extrativistas de recursos da floresta e criadores de animais domésticos, tais como galinhas, patos, porcos, entre outros. Assim, o quilombo de São Tomé de Tauçú é constituído por sujeitos, que transportam vínculos afetivos, simbólicos e culturais de sua ancestralidade, os quais configuram gestos, estilos e particularidades próprios.

Partindo de tais constatações, o referido quilombo possui, atualmente, 40 famílias, totalizando 160 pessoas, distribuídas em 25 casas, as quais possuem estrutura física simples, dotadas, algumas, de compartimentos com delimitações de quarto, de sala e de cozinha, cobertas com telhas de fibrocimento; outras, sem partes de paredes (fechadas com plásticos ou com lonas) e cobertas com palha. Um ponto relevante é que estas residências, assim como a igreja e o centro comunitário, estão organizadas no formato de vila (enfileiradas), entretanto, a maioria dessas casas encontra-se distanciada, mas fazem parte da área do quilombo e nele se localizam.

Frisa-se, ainda, que duas famílias dividem seis das residências mencionadas, em sistema de coabitação. Verificou-se, também, a existência de um campo de futebol, localizado atrás das residências, em que os quilombolas se reúnem, para jogar, no final da tarde.

Tratando-se da questão da organização social, o quilombo possui uma capela, uma sede comunitária (local em que acontecem programações festivas, como bingos, festas dançantes, aniversários, reuniões, etc., e que serve de salas de aula, abrigando turmas de $1^{\circ}$ ano a $5^{\circ}$ ano do Ensino Fundamental, uma vez que não existe escola) e um centro comunitário (espaço em que são produzidas as refeições, nos dias de eventos). O espaço do quilombo não conta com uma estrutura de atendimento básico de saúde (Figura 3).

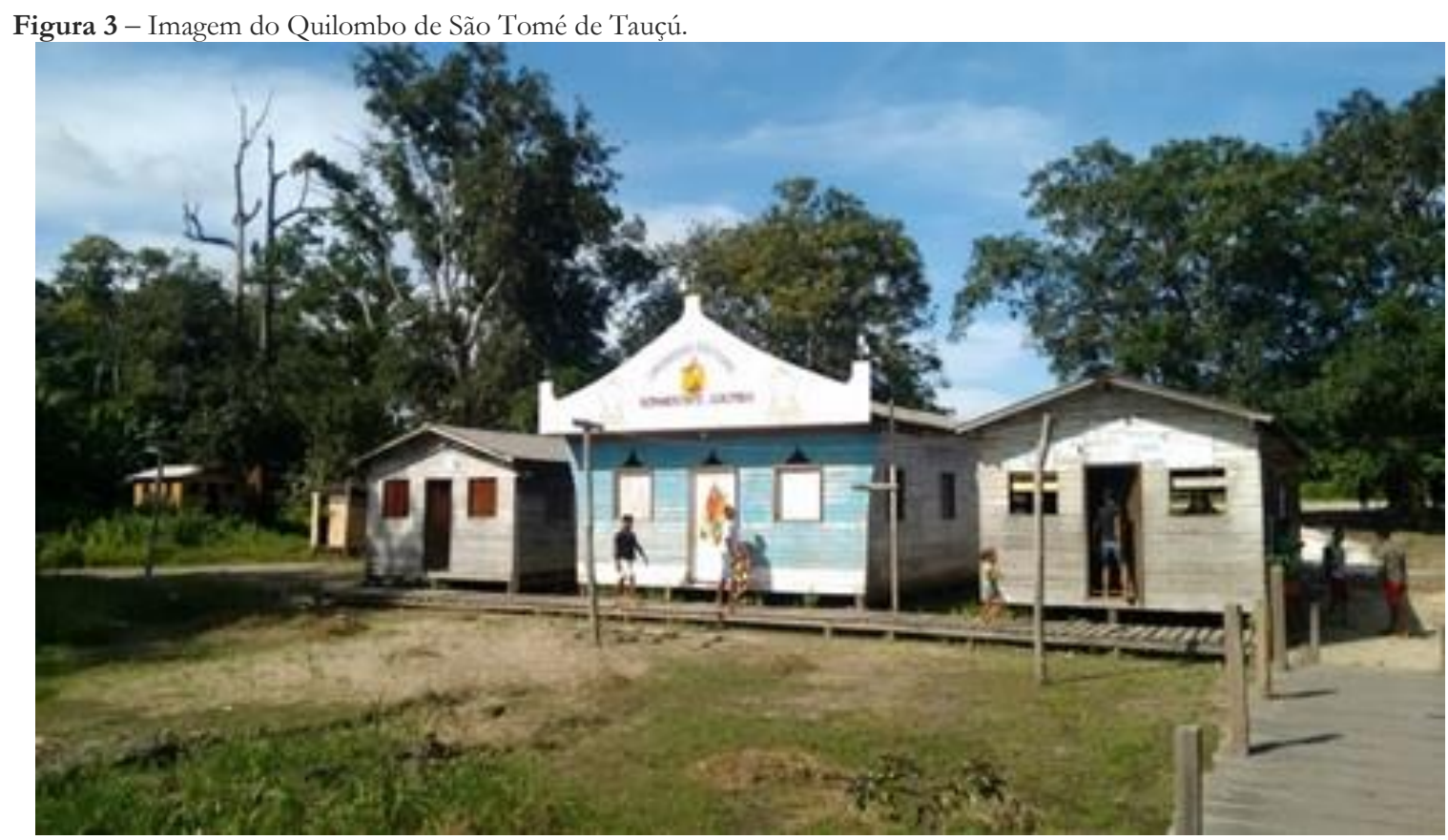

Fonte: Edinael Silva (2017).

O acesso a este quilombo se dá por via fluvial, em barcos de pequeno, de médio e de grande 
porte 9 . É importante frisar que há outros meios de transporte, a exemplo de canoas a remo, que são utilizadas para a pesca artesanal nos igarapés, para a extração do açaí e para deslocamento a locais mais próximos, e das rabetas ${ }^{10}$, que servem para o transporte rápido e para o deslocamento à cidade mais próxima.

Na cidade de Portel, os quilombolas comercializam sua produção (farinha, tapioca e frutos nativos da floresta) ${ }^{11}$ e, sobretudo, acessam o centro urbano, para adquirir produtos alimentícios industrializados e combustíveis (óleo diesel e gasolina), utilizados nos motores de transporte e na geração de energia. A duração das viagens varia de 30 minutos a duas horas, dependendo do meio de transporte e do sistema de marés.

Diante do que foi verificado nas pesquisas de campo, pode-se inferir que a economia do quilombo de São Tomé de Tauçú se sustenta na monocultura da mandioca e de seus derivados, com a participação familiar na produção (Figura 4A e 4B) e na coleta de frutos nativos da floresta.

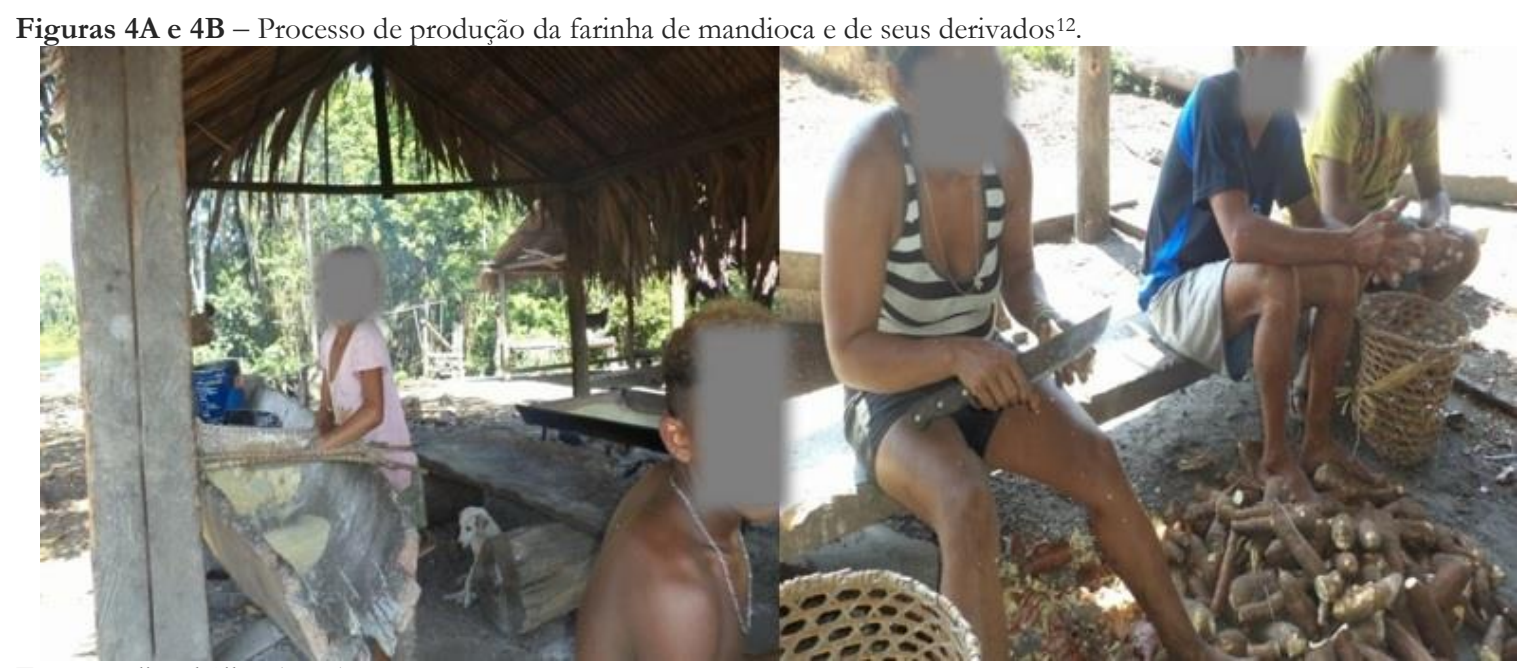

Fonte: Edinael Silva (2017)

Agregam-se, ao sistema produtivo, outros produtos, consumidos, exclusivamente, na comunidade, tais como: o açaí, a pesca e os animais, oriundos da caça. Lisboa (1997, p. 63), tratando das atividades econômicas desenvolvidas pelos moradores, observa que estas são determinadas pela necessidade de subsistência, que gira em torno das atividades agrícolas, da caça, da pesca e da coleta, havendo uma manipulação sistemática dos recursos naturais, de forma compatível com os meios de que dispõem e com critérios de uso destes recursos. Assim, pode-se afirmar que o quilombola de São Tomé de Tauçú é policultor, pois são múltiplas as atividades exercidas por estes sujeitos, na busca de sua sobrevivência e da de sua família.

Tal é o que depreende, a partir do relato de um morador: “(...) eu gosto dessa vida que nós leva aqui, é muito prazerosa, eu gosto de viver como nós vive porque aqui eu caço, pesco, faço

\footnotetext{
${ }^{9}$ Silva (2006) classificou, como barco de pequeno porte, aquele com capacidade de até uma tonelada; de médio porte, o que tem capacidade de uma até quatro toneladas; e de grande porte, aquele com capacidade superior a quatro toneladas.

${ }_{10}$ Rabetas: pequenas embarcações, com motor adaptado na parte traseira, com uma haste de aço comprida e uma hélice, no final.

${ }^{11}$ Farinha, tapioca e o tucupi são derivados da mandioca e são complementares, na alimentação dos quilombolas, assim como o piquía, a pupunha, o milho e o uxí, frutas que integram o café da manhã destes indivíduos.

12 Optou-se por não expor a identidade dos participantes da entrevista. As tarjas mantêm os entrevistados no anonimato, a pedido deles.
} 
roça, minhas plantação, jogo bola e vivo uma vida boa com minha família e meus zamigos (...)" (Depoimento 1, 2017).

Verifica-se, nesse relato, que o território é uma fonte de extração de recursos naturais, mas, também, o espaço que permite a subsistência, em que se criam e se recriam significados simbólicos (ações e comportamentos, experiências vividas, de pertencimento, de desejo e de intenção, presentes nas práticas e nas relações sociais, que constituem o território), em que se edifica a cultura e em que se compartilham os saberes, constituídos há muitas gerações.

É importante salientar que esses quilombolas sempre pautaram suas vivências na cronologia da natureza, no compasso do que se pode chamar de naturalidade temporal, figurada no entrelaçamento do quilombola com o rio e com a floresta, sem predeterminação, sem agendamento e sem horários estabelecidos. A jornada é determinada por ligações, por alianças, por vínculos de amizade, por partilhas de alimentos (peixes, caças), por produções de farinha e, sobretudo, pela presença dos chamados convidados ${ }^{13}$, os quais auxiliam no preparo das roças e na fabricação da farinha e dos seus derivados, além de tomar parte em outros eventos da comunidade. Como assevera Gonçalves (2015, p. 35), "a riqueza da floresta e a piscosidade dos rios permitia o desenvolvimento de uma economia natural, isto é, não monetizada".

Atualmente, percebe-se que este modo de vida, protagonizado pela comunidade tradicional, vem sendo influenciado, pela chegada de outros agentes (novos habitantes, sistema capitalista de produção, culturas diversas, processo tecnológico etc.), caracterizados por apresentarem temporalidades e modos de vida distintos dos vividos no quilombo, o que, nas palavras de La Blache (1954), pode provocar mudanças e adaptações na lógica de vida local.

Nota-se que a inserção de novos valores (hábitos, instrumentos e relações de trabalho e com a natureza, além da utilização de equipamentos e de objetos externos, como o rádio e a televisão e o uso do celular, da internet, etc.), de costumes diferenciados (o dormir em camas, o modo de se relacionar com os outros, os dialetos linguísticos, a culinária, etc.) e de crenças distintas (novas religiosidades, festas religiosas, etc.) alteram o modo de vida quilombola, promovendo um ajustamento, que vem se estabelecendo, no seio das populações tradicionais, sendo predominantemente considerado como o moderno, que, supostamente, se dispõe a apresentar avanços, em relação às condições originais de vida deste povo.

A vivência destes quilombolas, que outrora se fundamentava em um práticas diferentes das atuais, está se modificando, substancialmente, a partir do contato com agentes externos, que vêm se configurando como hegemônicos, em relação às populações tradicionais, principalmente, a partir do controle sobre o uso do território, que impossibilita aos quilombolas fazerem queimadas, derrubadas e extrações de recursos naturais, visto que a utilização destes elementos serve, apenas, para sua subsistência. Portanto, verifica-se que as novas disposições de uso do território estão provocando mudanças no modo de vida dos habitantes do quilombo de São Tomé de Tauçú.

Nesse sentido, é importante salientar que tais modificações também estão ocorrendo, por meio da utilização da força de trabalho de alguns dos membros do quilombo, por parte do poder público municipal, visto que existem transportadores de alunos e de professores, oriundos do próprio quilombo.

\footnotetext{
${ }^{13}$ A figura do convidado é uma recorrente, entre os sujeitos da comunidade, e ocorre, a partir do convite de um indivíduo a diversas pessoas, objetivando a concretização de um trabalho, seja a preparação de roças, seja a limpeza de uma área de floresta, para plantação de açaí, de macaxeira, de milho, etc., seja para a construção de casas e de estabelecimentos da comunidade, haja vista que, em contrapartida, esta pessoa oferta uma alimentação generosa.
} 
Certamente, percebe-se que os atuais habitantes do quilombo, que são funcionários públicos, não vivem mais como seus antepassados, ao ir e vir tradicional, pelos rios e pela floresta, à busca pelo pescado, à caça ou, mesmo, ao trabalho no roçado, uma vez que possuem um olhar cultural diferente, atendo-se as suas tarefas específicas, de incumbência do governo municipal. Este ponto de vista diferenciado foi observado, a partir de uma visita realizada na residência de um quilombola, que é funcionário público municipal (professor).

Durante esta visita, notou-se um novo padrão de conduta, que deve se repetir, nos próximos anos, no qual os indivíduos da residência possuem uma agenda e horários a cumprir, em sua ocupação, vinculada ao tempo-urbano, que se estende de segunda-feira a sexta-feira e engloba alguns sábados, de acordo com o calendário escolar. Notou-se, ainda, que a esposa do morador entrevistado (funcionário público) pouco se detinha aos trabalhos da roça e quando se dedicava a tal tarefa, o fazia em regime de parceria, junto a outros moradores. No caso das crianças dessa residência, elas dedicam seu tempo à escola e às brincadeiras, nos arredores da casa, ou à televisão. Verificou-se apenas um adolescente, que saiu ao rio, para pescar.

Portanto, a partir da pesquisa de campo, infere-se que a relação entre os habitantes do quilombo de São Tomé de Tauçú, seu modo de vida tradicional quilombola e, sobretudo, o uso de seu território, está sendo modificado, reestruturado e remodelado, a partir da criação, e da proximidade, do assentamento e de seus habitantes, com a interferência e com a anuência do poder público municipal. Para esclarecer melhor este fato, mostra-se, em um primeiro momento, o objetivo do assentamento, que é de estabelecer reserva específica de terras, para áreas de uso das comunidades do rio Acutipereira, as quais são gerenciadas por entidades governamentais, que determinam as normas e as formas de uso do território. Em um segundo momento, os sujeitos do próprio quilombo passam a exercer sua força de trabalho de outra maneira e, no compasso do tempo, vão-se esvaindo os laços e os costumes do sujeito policultor, que, hoje, se subordina, exclusivamente, ao emprego formal e comum dos espaços urbanos.

Ressaltamos que outros elementos corroboram, igualmente, para as modificações observadas, a exemplo dos programas sociais do Governo Federal (Bolsa Família, Bolsa Verde e Salário-maternidade), os quais explicam outras mudanças, que também estão ocorrendo no modo de vida tradicional amazônico.

Estas modificações que estão ocorrendo a partir do recebimento dos benefícios do Governo Federal, vem permitindo a estas pessoas adquirirem novos meios de produção, novos hábitos, estratégias de sobrevivência, modos de agir, vestir, calçar, dormir etc., pois, por meio do contato direto com novas tecnologias, culturas e hábitos se percebe as transformações que estão ocorrendo em seu modo de vida.

\section{CONSIDERAÇÕES FINAIS}

Tendo por base os enfoques apresentados neste trabalho, pode-se evidenciar que o modo de vida do quilombo de São Tomé de Tauçú se sustentou, e ainda se sustenta, em grande parte, pelas atividades econômicas da monocultura de mandioca e de seus derivados (farinha d'agua, farinha de tapioca, tucupi, etc.) ou por intermédio da pesca, da caça e da colheita de frutos da floresta. Comprovou-se, ainda, que, nas celebrações culturais, as festas religiosas têm maior destaque, haja vista que, no quilombo pesquisado, existe uma capela (igreja) católica. É em função de tais características que se estabelecem as territorialidades e que se reúnem conhecimentos, que são transmitidos hereditariamente, ou seja, entre as gerações dos habitantes deste 
quilombo.

Indubitavelmente, se descobriu, a partir da criação e da proximidade de um assentamento com o quilombo de Tauçú, que o dia a dia destes quilombolas vem sofrendo alterações, as quais se iniciam no espaço de sua vivência, no uso do seu território e em suas ações econômicas. Destaca-se, nesse sentido, em um primeiro momento, a sobreposição espacial do assentamento ao território dos quilombolas, deliberada por órgãos governamentais, os quais definem o modo de uso do território no assentamento e, consequentemente, o modo de subsistir neste espaço. Outro destaque se dá ao fato de que uma parcela da mão de obra quilombola passou a ser utilizada, pelo poder público municipal, com a definição de novas temporalidades, de novos objetos e de novas ações, desempenhadas por alguns dos quilombolas.

Assim, o modo de vida do quilombo estudado vem sendo modificado, a partir das influências do assentamento e do governo municipal, fato que tem ocasionado modificações no cotidiano tradicional dos quilombolas. Frente aos fatos observados, tornou-se evidente, ainda, que os fatores mencionados não são os únicos elementos a reestruturar o modo de vida dos quilombolas, pois a maioria das famílias é favorecida pelos programas Bolsa Família, Bolsa Verde, etc., elementos que colaboram para a alteração do modo de vida quilombola, uma vez que permitem o surgimento de novos costumes e de atividades com características eminentemente externas, o que pode implicar o esquecimento da transmissão das atividades tradicionais quilombolas, bem como o seu desaparecimento, no futuro.

\section{REFERÊNCIAS}

ALMEIDA, Alfredo Wagner Berno de. Os Quilombos e as Novas Etnias. In: O’DWYER, Eliane Cantarino (org.). Quilombos: identidade étnica e territorialidade. Rio de Janeiro: Editora FGV, 2002. p. 43-82.

BRASIL. Constituição da República Federativa do Brasil de 1988. Brasília: Editora do Senado, 1988.

CASTRO, E. Território, biodiversidade e saberes de populações tradicionais. Papers do NAEA, Belém, n. 92, 1998.

DIEGUES, A. C.; ARRUDA, R. S. V. (Org.). Saberes tradicionais e biodiversidade no Brasil. Brasília: Ministério do Meio Ambiente; São Paulo: USP, 2001.

FERRAZ, M. G. B; CARDOSO, A. L. R. Floresta Nacional de Caxiuanã: patrimônio biológico e cultural da Amazônia. Belém: Museu Paraense Emilio Goeldi, 2012.

GUSMÃO, N. M. M. de.; Da antropologia e do direito: impasses da questão negra no campo. Fundação Cultural palmares. Brasília. 1999.

HAESBAERT, R. Território e Multiterritorialidade: um debate. GEOgraphia, Rio de Janeiro, ano 11, n. 17, p. 19-44, mar. 2007.

INSTITUTO NACIONAL DE COLONIZAÇÃO E REFORMA AGRÁRIA/ASSENTAMENTOS (INCRA). Disponível em: http:/ /www.incra.gov.br. Acesso em: 12 jul. 2017.

LA BLACHE, P. V. de. Princípios de geografia humana. Tradução de Fernando Martins. 2. ed. Lisboa: Cosmos, 1954.

LISBOA, P. L. B. (Org). Caxiuanã. Belém: Museu Paraense Emilio Goeldi, 1997.

MOREIRA, R. O que é Geografia? 14 ed. São Paulo: Brasiliense, 1994. (Coleção Primeiros Passos, n. 48).

NAHUM, J. S. De ribeirinha a quilombola: dinâmica territorial de comunidades rurais na Ama- 
zônia paraense. Campo e Território: Revista de Geografia Agrária, v. 6, n. 12, p. 79-103, ago. 2011.

NEVES, D. P. Os ribeirinhos-agricultores de várzea: formas de enquadramento institucional. Novos Cadernos NAEA, v. 12, n. 1, p. 67-92, jun. 2009.

PORTO-GONÇALVES, C. W. Amazônia, Amazônias. São Paulo: Contexto, 2015.

GOTTMANN, J. The significance of territory. Charlottesville: University of Virginia Press, 1973.

RAFFESTIN, C. Por uma geografia do poder. São Paulo: Ática, 1993.

SANTOS, M. O dinheiro e o território. GEOgraphia, Rio de Janeiro, Ano 1. n. 1, p. 7-13, 1999.

SANTOS, M. O papel ativo da geografia: um manifesto. In: Anais do Encontro Nacional de Geógrafos, Florianópolis, 2000. Florianópolis, 2000.

SANTOS, M.; SILVEIRA, M. L. O Brasil: território e sociedade no início do século XXI. São Paulo: Record, 2001.

SAQUET, M. A. Por uma abordagem territorial. In: SAQUET, M. A.; SPOSITO, E. S. (Org.) Território e Territorialidades: teorias, processos e conflitos. 1 ed. São Paulo: Expressão Popular, 2009. p. 73-94.

SCHMITT, A.; TURATTT, M. C. M. e CARVALHO, M. C. P. A atualização do conceito de quilombo: identidade e território nas definições teóricas. Ambiente \& Sociedade. [online]. 2002, n.10, p. 129-136.

SILVA, C. N. Territorialidades e modo de vida de pescadores do rio Ituquara, BrevesPA. 2006. Dissertação (Mestrado em Geografia) - Centro de Filosofia e Ciências Humanas, Universidade Federal do Pará, Belém, 2006. 